PREPARED FOR THE U.S. DEPARTMENT OF ENERGY, UNDER CONTRACT DE-AC02-76CH03073

PPPL-3485

PPPL-3485

UC-70

\author{
Status of Far Infrared Tangential \\ Interferometry/Polarimetry (FIReTIP) on NSTX
}

by

H.K. Park, S. Edwards, L. Guttadora, B. Deng, C.W. Domier, K.C. Lee, M. Johnson, and N.C. Luhmann, Jr.

August 2000

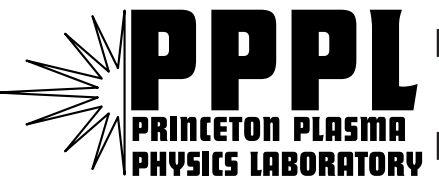

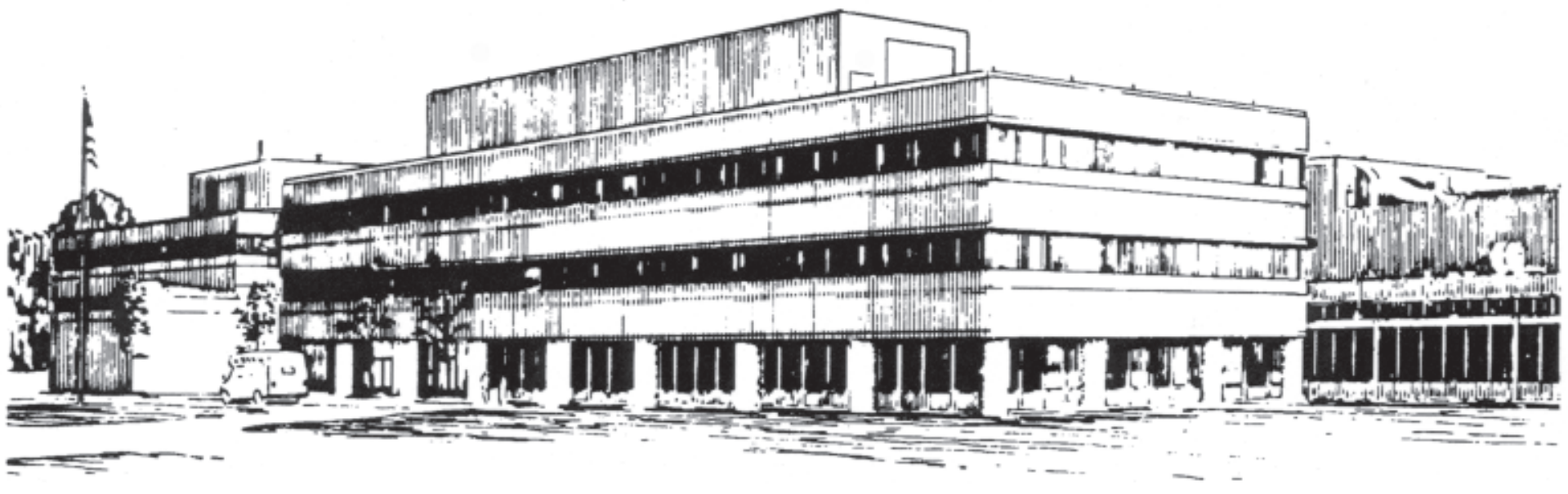

PRINCETON PLASMA PHYSICS LABORATORY PRINCETON UNIVERSITY, PRINCETON, NEW JERSEY 


\section{PPPL Reports Disclaimer}

This report was prepared as an account of work sponsored by an agency of the United States Government. Neither the United States Government nor any agency thereof, nor any of their employees, makes any warranty, express or implied, or assumes any legal liability or responsibility for the accuracy, completeness, or usefulness of any information, apparatus, product, or process disclosed, or represents that its use would not infringe privately owned rights. Reference herein to any specific commercial product, process, or service by trade name, trademark, manufacturer, or otherwise, does not necessarily constitute or imply its endorsement, recommendation, or favoring by the United States Government or any agency thereof. The views and opinions of authors expressed herein do not necessarily state or reflect those of the United States Government or any agency thereof.

\section{Availability}

This report is posted on the U.S. Department of Energy's Princeton Plasma Physics Laboratory Publications and Reports web site in Calendar Year 2000. The home page for PPPL Reports and Publications is: http://www.pppl.gov/pub_report/

DOE and DOE Contractors can obtain copies of this report from:

U.S. Department of Energy

Office of Scientific and Technical Information

DOE Technical Information Services (DTIS)

P.O. Box 62

Oak Ridge, TN 37831

Telephone: (865) 576-8401

Fax: (865) 576-5728

Email: reports@adonis.osti.gov

This report is available to the general public from:

National Technical Information Service

U.S. Department of Commerce

5285 Port Royal Road

Springfield, VA 22161

Telephone: $1-800-553-6847$ or

(703) $605-6000$

Fax: (703) 321-8547

Internet: http://www.ntis.gov/ordering.htm 


\title{
Status of Far Infrared Tangential Interferometry/Polarimetry (FIReTIP) on NSTX
}

\author{
H.K. Park, S. Edwards, and L. Guttadora \\ Princeton Plasma Physics Laboratory, P.O. Box 451, Princeton, New Jersey 08543 \\ B. Deng, C.W. Domier, K.C. Lee, M. Johnson and N.C. Luhmann, Jr. \\ Department of Applied Science, University of California at Davis, California 95616
}

\begin{abstract}
The Influence of paramagnetism and diamagnetism will significantly alter the vacuum toroidal magnetic field in spherical torus. Therefore, plasma parameters dependent upon $\mathrm{B}_{\mathrm{T}}$ such as the q-profile and local $\beta$ value needs an independent measurement of $\mathrm{B}_{\mathrm{T}}(\mathrm{r}, \mathrm{t})$. The multi-chord Tangential Far Infrared Interferometer/ Polarimeter (FIReTIP) system [1] currently under development for National Spherical Torus Experiment (NSTX) will provide temporally and radially resolved toroidal field profile $\left[\mathrm{B}_{\mathrm{T}}(\mathrm{r}, \mathrm{t})\right]$ and 2-D electron density profile $\left[\mathrm{n}_{\mathrm{e}}(\mathrm{r}, \mathrm{t})\right]$ data. Two channel interferometer will be operational this year and full system will be ready by 2002 .
\end{abstract}

\section{Introduction}

In conventional tokamaks, it is well known that the strength of the toroidal magnetic field $\left(\mathrm{B}_{\mathrm{T}}\right)$, which is one of the fundamental parameters, is modified very little in the presence of plasmas. Important plasma parameters such as "safety factor $(q)$, local $\beta$ and magnetic shear are consequently estimated based on the use of the vacuum magnetic field strength without independent measurement. However, the vacuum magnetic field in NSTX, is expected to be altered significantly in the presence of plasmas. Therefore, it is essential to have an independent measurement of the toroidal magnetic field in NSTX, in order to address changes in plasma parameters dependent upon on toroidal field strength. The technique based on Faraday rotation effect has evolved and been applied routinely in machines where accessibility is not a problem. The primary goal of FIReTIP system is the measurement of the toroidal magnetic field, thus answering one of the perceived needs for diagnostic for NSTX. The toroidal magnetic field data can also be used in conjunction with the MSE measurement of pitch angles to obtain the q-profile. Simultaneously, temporally resolved (up to $\sim 500 \mathrm{kHz}$ ) 2D density profile information will be available as well. Since the laser wavelength of $119 \mu \mathrm{m}$ is an ideal wavelength for NSTX parameters, the experimental design will be based on accumulated knowledge and hardware from TFTR multichannel infrared interferometer [MIRI] system [2].

\section{Laser system and basic techniques}

In interferometry/polarimetry system, the O-mode polarized radiation in the magnetically confined plasma undergoes a phase shift given by

$$
\phi(x)=2.8 \times 10^{-15} \lambda \int_{0}^{x} n\left(x^{\prime}\right) d x^{\prime}
$$


In the presence of a parallel magnetic field component, $B \mathrm{~T}$, the polarization of the wave is Faraday rotated through an angle

$$
\Psi(x)=2.6 \times 10^{-13} \lambda^{2} \int_{0}^{x} n\left(x^{\prime}\right) B_{\mathrm{T}}\left(x^{\prime}\right) d x^{\prime}
$$

With a sufficient number of chords spanning the plasma, interferometry data can be inverted to yield the temporally and radially resolved plasma density $\mathrm{n}_{\mathrm{e}}(r, t)$. Polarimetry data can be subsequently inverted to yield the time dependent parallel magnetic field $\mathrm{B}_{\mathrm{T}}(r, t)$.

The FIReTIP system design for NSTX is based on a wavelength of $119 \mu \mathrm{m}$ that is ideal for NSTX plasma parameters. At this wavelength, the expected signal to noise ratio for interferometry and polarimetry is excellent. Interferometer system will have $\sim 10$ fringes shift and polarimetry system will have a Faraday rotation of $\sim 10$ degrees while a refraction of the beam is at the minimum (less than $\sim 0.5 \mathrm{~mm}$ ) as shown in Fig. 3 in reference 1. Due to an access limitation, the present system consists of seven beam lines that enter at three separate toroidal locations at Bay $\mathrm{K}$ on NSTX as shown in Fig. 1. Each beam traverses a different chord along the horizontal midplane of the device, reflects from a suitably placed corner cube retro-reflector, and traverses back through the plasma to return to a common point for detection. This scheme is shown schematically in this figure. Currently we are planning to operate two channel interferometry system (\#1 and \#2 in Fig. 1) and test the polarimetry channels.

There has been a significant progress of Faraday rotation measurement. The technique we are implementing on this system is modulation of polarization of the probe beam. A major limitation of the rotating half-wave plate used in MTX measurement is the limited modulation rate $(<10$ $\mathrm{kHz}$ ) that can be created by the mechanically rotating plate. This limitation can be removed by replacing the rotating plate by an additional far-infrared (FIR) laser. In this approach pioneered by Rommers and Howard on RTP [3], the rotating elliptically polarized wave is formed by injecting two co-aligned counter-rotating circularly polarized laser beams into the plasma. This scheme is illustrated in Fig. 4 of reference 1. The beams, generated by separate FIR lasers with frequencies $\omega_{1}$ and $\omega_{2}$, are slightly offset to allow the use of heterodyne detection methods.

The FIReTIP system will utilize an approach similar to that used on RTP. In this case, however, the FIR lasers will run at $119 \mu \mathrm{m}$ with a difference frequency $\omega_{1}-\omega_{\mathrm{LO}}=4.0 \pm 0.5 \mathrm{MHz}$ and $\omega_{2}-\omega_{\mathrm{LO}}=6.0 \pm 0.5 \mathrm{MHz}$. The LO frequency shift of $5 \mathrm{MHz}$ will be obtained using the Stark tuned FIR laser in addition to two FIR lasers operating with a frequency difference of $2 \mathrm{MHz}$. This generates interferometer and a polarimeter signal at 6.0 and 4.0 MHz. Phase lock loop circuits and with a tracking system will be utilized to examine the interferometer signal(s), while a phaselocked quadrature phase comparator system will be developed to make Faraday rotation measurements with high temporal resolution [4]. Note that only a single detector is required for each chord in the tangential interferometer system.

\section{Optical system configuration}

The beam propagation is largely divided into three sections. First and second sections consist of two focusing mirrors that collimate the laser beams (effective beam waist of $\sim 0.4 \mathrm{~cm}$ ) to an appropriate size (beam waist of $\sim 2.2 \mathrm{~cm}$ ) so that splitting and detection can be arranged with collimated beams. The final section is propagation through the plasma and retro-reflectors.

The partial layout of optical components is shown for the first three channels in Fig. 2. Electroformed $\mathrm{Cu}$ meshes will be utilized as beam splitters and partial reflectors. The 
characteristics of these metal meshes are studied in detail [5] and known to distort beam polarizations for non-normal incidence. In order to split the probing beam into seven parts which will be directed to retroreflectors with a minimum polarization change, the reflection angles are maintained 10 degree. Splitting the LO beam into seven parts can be achieved with these beam splitters too. They will be directed to each of the Schottky diode corner cube detectors and polarizing grids with which the interferometer and polarimeter signals are to be measured.

Each beam will be guided to the mid-plane where quartz windows are located at Bay $\mathrm{K}$ of NSTX as shown in Fig. 3. The thickness of crystal quartz is adjusted so that the reflection at the surface is minimum for this wavelength. For channels \# 1 and \#2, two exit windows are located at Bay $\mathrm{F}$ where retroreflectors are mounted on the base plate of the Thomson scattering detection system.

Since this system consists of retro-reflectors mounted on the wall of vacuum vessel and outside mounts, the identification of a possible vibration effect on the channels using inside retroreflectors, even though the fringe shift is expected to be large ( $\sim 10$ fringes), will be considered during this run time.

\section{Summary}

It is essential to make a measurement of time dependent toroidal field variation in NSTX, since paramagnetism and diamagentism will alter the vacuum magnetic field significantly in the presence of plasmas. This paper presents a multi-purpose Tangential Interferometer/ Polarimeter system to measure $B_{T}(r, t)$ and $n_{e}(r, t)$, simultaneously. In addition, it is possible to measure chord integrated frequency spectrum from both coherent and incoherent density fluctuations.

\section{Reference}

[1] H. Park, C. Domier, W.R. Geck and N.C. Luhmann, Jr., "Far infrared Tangential Interferometry/Polarimetry on the NSTX,") Review of Scientific Instruments 70, pp. 710-713 (1999).

[2] D.K. Mansfield, H.K. Park, L.C. Johnson, H. Anderson, S. Foote, B. Clifton and C.H. Ma, "Multichannel Far-Infrared Laser Interferometer for Electron Density Measurements on the Tokamak Fusion Test Reactor," Applied Optics 26, pp. 4469-4474 (1987).

[3] J.H. Rommers, A.J.H. Donn, F.A. Karelse and J. Howard, "The Multichannel Triple-Laser Interferometer/Polarimeter System at RTP," Review of Scientific Instruments 68, pp. 12171226 (1997).

[4] C.W. Domier, W.A. Peebles, and N.C. Luhmann, Jr., "Millimeter-Wave Interferometer for Measuring Plasma Electron Density," Review of Scientific Instruments 59, pp. 1588-1590 (1988).

[5] Y.S. Hwang and H.K. Park, "Polarization Characteristics of Wire Mesh at $119 \mu \mathrm{m}$," Applied Optics 28, pp. 4999-5001 (1989). 


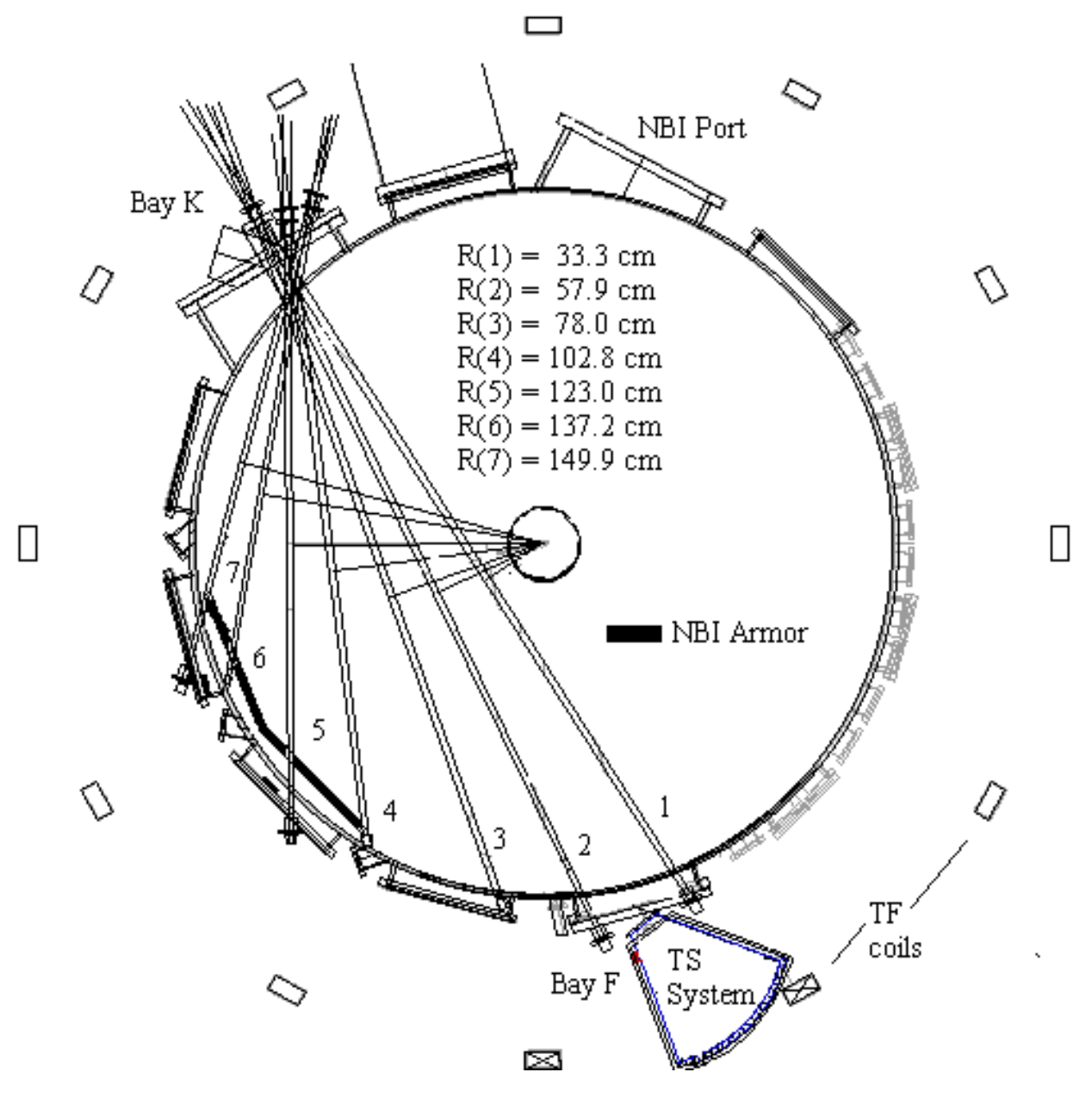

Fig. 1. Seven channel FIReTIP system will have fan view of beam lines. Three entrance windows and tangencies of each beam lines are provided. 


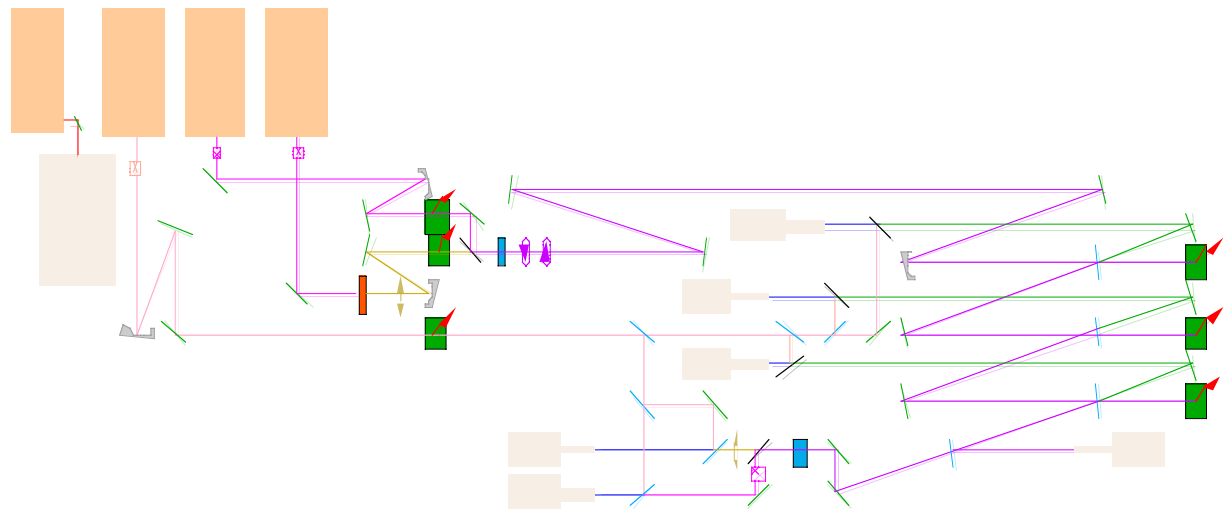

Fig. 2. Optical arrangement for the first three channels. 


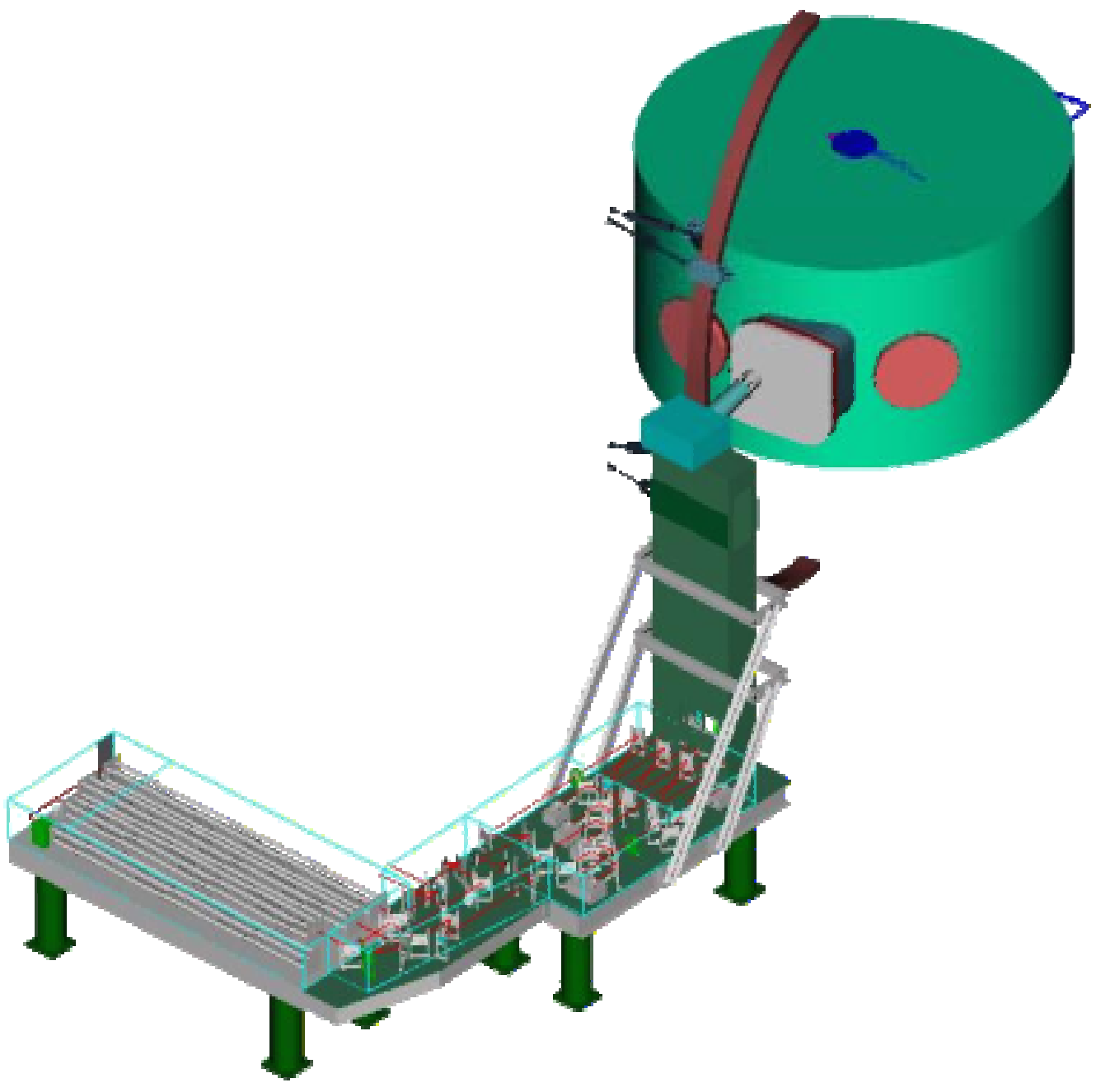

Fig. 3. 3-D CAD design of FIReTIP system. Beams from the optical table are entering the window at Bay $\mathrm{K}$ through optical tower. 
The Princeton Plasma Physics Laboratory is operated by Princeton University under contract with the U.S. Department of Energy.

\author{
Information Services \\ Princeton Plasma Physics Laboratory \\ P.O. Box 451 \\ Princeton, NJ 08543
}

Phone: 609-243-2750

Fax: 609-243-2751

e-mail: pppl_info@pppl.gov

Internet Address: http://www.pppl.gov 